\title{
Evaluation of Serum Anion gap in the three trimesters of Pregnancy in a Christian Religious Hospital in Benin City, Nigeria
}

\author{
${ }^{* 1}$ OMOROGIUWA, A; OZOR, MO \\ "Department of Physiology, School of Basic Medical Sciences, College of Medical Sciences, \\ University of Benin City, Benin City, Nigeria \\ ${ }^{\#}$ Department of Physiology, Faculty of Basic Medical Sciences, \\ College of Medical Sciences, \\ Ambrose Alli University, Ekpoma, Nigeria \\ Corresponding author: E-mail: ask4ade2006@yahoo.com Phone number: +234(0)7039460340
}

\begin{abstract}
This study is aimed at determining anion gap in the three trimesters of pregnancy. The study involved a total of 80 volunteers from the St. Philomena Catholic hospital, Benin City. The volunteers comprised 20 nonpregnant control, and 20 pregnant women in each of the three trimesters of pregnancy. Ethical approval was obtained from the Ethics and Collaboration committee of the hospital. Informed consents were also obtained from the participants. With strict aseptic method blood samples were drawn from the ante cubital vein into a lithium heparin bottle for electrolyte analysis using standard laboratory methods. Anion gap was subsequently calculated using the formula; $\left(\left[\mathrm{Na}^{+}\right]+\left[\mathrm{K}^{+}\right]\right)-\left(\left[\mathrm{Cl}^{-}\right]+\left[\mathrm{HCO}^{-}\right]\right)$. Results were compared using the student's t-test and $\mathrm{p}<0.05$ were considered statistically significant. The anion gap for the first trimester of pregnancy $(11.01 \pm 0.13 \mathrm{mmol} / \mathrm{L})$ was significantly lower $(\mathrm{p}<0.05)$ than that of the control group $(14.90 \pm 0.43 \mathrm{mmol} / \mathrm{L})$. The anion gaps for the second $(14.78$ $\pm 0.07 \mathrm{mmol} / \mathrm{L})$ and third trimesters of pregnancy $(14.90 \pm 0.11 \mathrm{mmol} / \mathrm{L})$ were essentially the same as that of the control subjects. The results may have been due to the variation in the gastrointestinal symptoms associated with the first trimester of pregnancy. However, the study indicates that pregnant women in their first trimester are more prone to abnormal serum anion gap which is a function of blood electrolyte concentration. This finding should be reflected by antenatal care givers and antenatal care policy makers to forestall untoward effect of abnormal serum anion gap. CJASEM
\end{abstract}

http://dx.doi.org/10.4314/jasem.v20i4.22

Keywords: Anion Gap, Electrolyte, Trimester, Pregnancy

Pregnancy is marked by profound changes in a woman's hormonal status and metabolism (ZavalzaGo mez et al., 2008). It is also a condition of chronic period of volume overload in which hypervolumia is the result of active sodium and water retention primarily induced by the activation of reninangiotensin system (Sala et al., 1995). The ability to regulate nutrient balance during this period is critical to the health of the mother and the growing fetus (Kirwan et al., 2002). The normal human pregnancy last for about 40 weeks as measured from the day of the last menstrual cycle (Coffey Boyle et al., 2000) and it is usually divided into three intervals called trimesters with each beginning a little longer than 13 weeks (Majzoub, 2000). Generally, the first trimester ends at the beginning of the $13^{\text {th }}$ week, which is the three completed months of pregnancy. The second trimester usually ends at the end of the $27^{\text {th }}$ week. The third trimester can end anywhere between the $38^{\text {th }}$ and $42^{\text {nd }}$ week (Majzoub, 2000). Among other adaptations, each trimester is associated with renal, gastrointestinal and cardiovascular alterations which help to maintain feto-maternal well-being. A deviation from the normal function of the gastrointestinal and renal system can alter the acidbase balance of the pregnant woman. This alteration ultimately affects the anion gap which is a function of the electrolytes; sodium, potassium, chloride and bicarbonate.

The anion gap being a function of electrolytes can be affected by gastrointestinal symptoms such as vomiting, anorexia other symptoms suggestive of renal pathologies. The anion gap ( $\mathrm{Oh}$ and Carroll, 1977., Gabow et al., 1980) is the difference in the measured cations (positively charged ions) and the measured anions (negatively charged ions) in serum, plasma, or urine.

The magnitude of this difference (i.e., "gap") in the serum is often calculated in medicine when attempting to identify the cause of metabolic acidosis i.e. lower than normal $\mathrm{Ph}$ in the blood. If the gap is greater than normal, then the anion gap metabolic acidosis is diagnosed. The term "anion gap" usually implies serum anion gap, but the urine anion gap is also clinically useful measure (Kirschbaum et al., 1999). Calculating the anion gap is clinically useful, as it helps in the differential diagnosis of a number of disease states. 
Each trimester of pregnancy brings with it changes which affects maternal biochemical and hematological parameters, resulting in an increase or decrease over the normal non-pregnant values. The first trimester of pregnancy for instance is associated with nausea, anorexia and vomiting. These gastrointestinal symptoms might compromise serum electrolyte concentration and serum albumin levels. This compromise can be assessed by the anion gap. This study is therefore aimed at comparing anion gap in non-pregnant women and women in the three trimesters of pregnancy.

\section{MATERIALS AND METHODS}

Study population: A total of eighty volunteers from the St Philomena Catholic Hospital, comprising 20 subjects in each of the three trimesters of pregnancy and 20 non-pregnant, non-lactating and aged matched control subjects, while the test subjects were 20 each in the three trimesters of pregnancy. Exclusion criteria: Subjects with Anemia, Human Immunodeficiency Virus, Hepatitis, renal disease and other chronic illnesses were excluded from the study.

Inclusion criteria: The test subjects included for the study were apparently healthy booked patients who had booking laboratory investigation results that were within normal range. The control subjects were apparently healthy staff of the hospital.

Data and sample collection: Demographic data were obtained by using a semi-structured questionnaire. Blood pressure was measured using a mercury sphygmomanometer. Blood samples were drawn from the ante-cubital vein of each subject into lithium heparin tubes for the determination of electrolytes.

Measurement of blood pressure: Following a rest period of about 30 minutes in the hospital, the systolic and diastolic pressures were measured in each subject on the brachial artery using the auscultatory method. Diastolic pressure was determined as the disappearance of the Korotkoff's sound.

Determination of serum electrolytes (Sodium, Potassium, Chloride and Bicarbonate): Five (5mls) of blood was drawn from the antecubital vein of each subject into a lithium heparin bottle following aseptic procedure. The blood samples were then centrifuged and sera samples obtained were used for the analyses of electrolytes (sodium, potassium, chloride and bicarbonate) levels. Serum sodium and potassium concentrations were determined using flame emission photometry method of Magoshes and Vallee (1956), which was based on the desolvation of solution containing these elements by a flame, leaving solid (salts), which dissociates to neutral ground state atoms. These atoms become excited in the flame, thus moving to a higher energy state and the excited atoms fall back to the ground state, light of characteristic wavelength is emitted (589 nm for sodium and $768 \mathrm{~nm}$ for potassium). This light then passes through a suitable filter onto a photosensitive element and the amount of current produced is measured and this is proportioned to the amount of sodium or potassium present in the original sample. Serum chloride ion was determined by titration method (Schales and Schales, 1941). The sample was titrated with a standardized mercuric nitrate solution in the presence of diphenylcarbazone as an indicator. Chloride ions $\left(\mathrm{Cl}^{-}\right)$in the sample combine with mercuric ions $(\mathrm{Hg}+)$ to form mercury chloride $(\mathrm{HgCl}$ ), a colorless, soluble, but only slightly ionized compound. As long as chloride ions are present, mercuric ions preferentially react with them. At the end point, when all chloride ions have been complexed, the excess mercuric ions produce a violet color in the presence of diphenylcarbazone.. Serum bicarbonate was estimated by titration method (Van Slyke and Neil 1924). The method is based on the release of carbon dioxide from bicarbonate ion in serum with dilute hydrochloric acid. The excess acid was then titrated with sodium hydroxide using phenol red as indicator.

Calculation of anion gap: Anion gap $=\left(\left[\mathrm{Na}^{+}\right]+\right.$ $\left.\left[\mathrm{K}^{+}\right]\right)-\left(\left[\mathrm{Cl}^{-}\right]+\left[\mathrm{HCO}_{3}^{-}\right]\right) \ldots$ Equation 1

Where, $\left[\mathrm{Na}^{+}\right]$is serum concentration of Sodium, $\left[\mathrm{K}^{+}\right]$is serum concentration of Potassium, $\left[\mathrm{Cl}^{-}\right]$is serum concentration of Chloride and $\left[\mathrm{HCO}_{3}{ }^{-}\right]$is serum concentration of Bicarbonate

Determination of Progesterone and Estrogen: Blood samples were obtained from a jugular vein using vacutainer vials and centrifuged immediately after collection at $3000 \mathrm{rpm}$ for 10 minutes. Concentrations of progesterone were determined by ELISA kit (Monobind $\AA$; USA) with $0.1 \mathrm{ng} / \mathrm{ml}$ sensitivity. The plasma estradiol $\left(\mathrm{E}_{2}\right)$ concentration was measured by ELISA kit (DRG International, $\mathrm{GmbH}$, USA) with $0.000625 \mathrm{ng}$. / mL sensitivity.

Statistical analysis: Data were presented as percentages and mean value \pm standard error of mean. The means were tested for homogeneity using one way analysis of variance of Micro soft excels 2010 and the significance between means was tested using the Duncan post hoc test of SPSS version 16. A difference between two means was considered to be statistically significant with a $\mathrm{p}$ value $<0.05$. 


\section{RESULTS AND DISCUSSION}

The age for test and control subjects ranged from 25 to 30 years. The systolic and diastolic blood pressures were $120.1 \pm 11.3$ and $77.2 \pm 10.1 \mathrm{mmHg}, 120.4 \pm 9.3$ and $76.5 \pm 10.0 \mathrm{mmHg}, 121.5 \pm 8.9$ and $77.7 \pm 9.9$
$\mathrm{mmHg}, \quad 121.4 \pm 9.4$ and $77.6 \pm 11.1 \mathrm{mmHg}$ for the control, first trimester, second trimester and third trimester respectively. There were no significant difference $(p>0.05)$ between the systolic and diastolic blood pressures of the test subjects and control.

Table 1: Showing the Percentage Distribution of symptoms in the Non-Pregnant Control and the trimesters of pregnancy

\begin{tabular}{llllllll}
\hline Symptoms & NPC & \multicolumn{2}{l}{ FTP; n=20 } & \multicolumn{3}{c}{ STP; n=20 } & \multicolumn{3}{c}{ TTP; n=20 } \\
\cline { 3 - 7 } & n=20 & \%WOS & $\%$ WS & $\%$ WOS & $\%$ WS & $\%$ WOS & $\% W S$ \\
Nausea & Nil & $3(15 \%)$ & $17(85 \%)$ & $18(90 \%)$ & $02(10 \%)$ & $19(95 \%)$ & $1(05 \%)$ \\
Vomiting & Nil & $8(40 \%)$ & $12(60 \%)$ & $20(100 \%)$ & Nil & Nil & Nil \\
Anorexia & Nil & $3(15 \%)$ & $17(85 \%)$ & $18(90 \%)$ & $02(10 \%)$ & $19(15 \%)$ & $17(85 \%)$ \\
Constipation & Nil & $16(80 \%)$ & $4(20 \%)$ & $8(40 \%)$ & $12(60 \%)$ & $6(30 \%)$ & $14(70 \%)$ \\
Nocturia & Nil & Nil & Nil & Nil & Nil & $2(10 \%)$ & $18(90 \%)$ \\
\hline
\end{tabular}

NPC; Non-pregnant control, FTP; First trimester of pregnancy, STP; Second trimester of pregnancy, TTP; Third trimester of pregnancy, \%WS; Percentage with symptoms, \%WOS ; Percentage without symptoms.

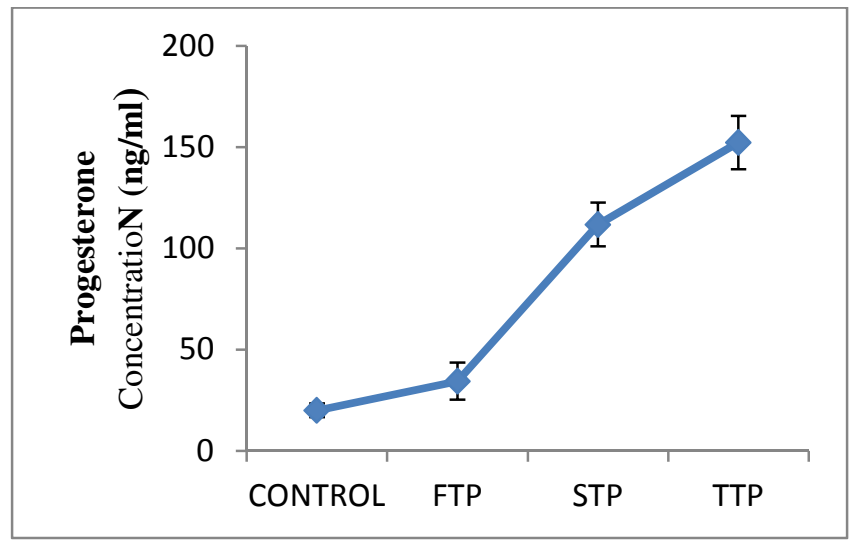

Fig 1: Serum progesterone concentration in non-pregnant control and pregnancy

FTP; First trimester of pregnancy, STP; Second trimester of pregnancy, TTP; Third trimester of pregnancy

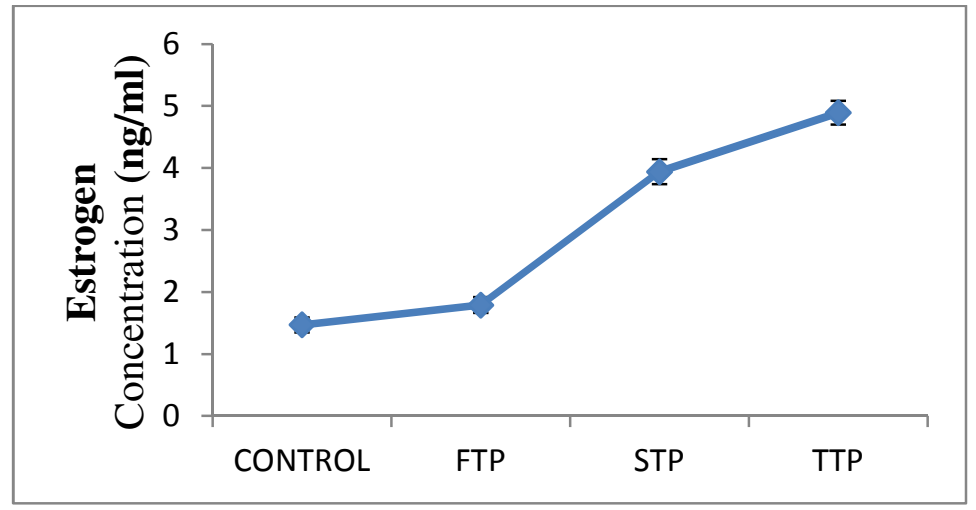

Fig 2: Serum estrogen concentration in non-pregnant control and pregnancy.

FTP; First trimester of pregnancy, STP; Second trimester of pregnancy, TTP; Third trimester of pregnancy 
Table 2: Serum electrolyte concentration for control and the trimesters of pregnancy

\begin{tabular}{lllll}
\hline $\begin{array}{c}\text { Electrolytes } \\
(\mathbf{m m o l} / \mathbf{L})\end{array}$ & Control; $\mathbf{n = 2 0}$ & $\mathbf{F T P} ; \mathbf{n}=\mathbf{2 0}$ & $\mathbf{S T P} ; \mathbf{n = 2 0}$ & TTP; $\mathbf{n = 2 0}$ \\
\hline Sodium & $142.85 \pm 0.83$ & $138.36 \pm 1.27$ & $144.56 \pm 0.79$ & $142.15 \pm 0.54$ \\
Potassium & $3.62 \pm 0.02$ & $3.00 \pm 0.02$ & $2.97 \pm 0.02$ & $3.27 \pm 0.09$ \\
Bicarbonate & $25.12 \pm 0.38$ & $26.25 \pm 0.30$ & $24.93 \pm 0.92$ & $25.00 \pm 0.30$ \\
Chloride & $106.45 \pm 0.90$ & $104.10 \pm 1.12$ & $107.82 \pm 0.59$ & $105.52 \pm 0.22$ \\
\hline
\end{tabular}

FTP $=$ First trimester of pregnancy, STP $=$ Second trimester of pregnancy,

$\mathrm{TTP}=$ Third trimester of pregnancy

Anion Gap $($ control $)=([142.85]+[3.62]-[106.45]+[25.12])=14.90 \pm 0.43 \mathrm{mmol} / \mathrm{L}$

Anion $\mathrm{Gap}_{\text {FTP }}=([139.36]+[3.00])-([104.10]+[26.25])=11.01 \pm 0.13 \mathrm{mmol} / \mathrm{L}$

Anion Gap $_{\text {STP }}=([144.56]+[2.97])-([107.82]+[24.93])=14.78 \pm 0.07 \mathrm{mmol} / \mathrm{L}$

Anion $\mathrm{Gap}_{\mathrm{TTP}}=([142.15]+[3.27])-([105.52]+[25.00])=14.90 \pm 0.11 \mathrm{mmol} / \mathrm{L}$

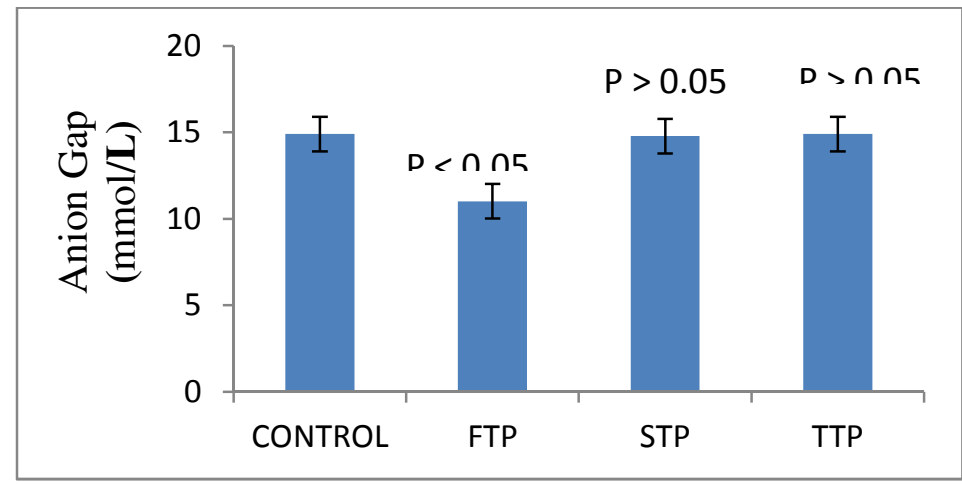

Fig 3: Anion gap in non-pregnant control and the trimesters of pregnancy. $\mathrm{p}<0.05$ implies statistically significant and $\mathrm{p}>0.05$ implies not statistically significant when compared to control.

Pregnancy is a special state with physiologic, biochemical and anatomical changes that ensures feto-maternal well-being. Each trimester of pregnancy has own specific adaptive changes. In this study, it was observed that the first trimester of pregnancy is associated with some gastrointestinal symptoms such as nausea, anorexia and vomiting (Table 1) which are capable of affecting electrolyte concentration. Studies have suggested that these gastrointestinal changes are traceable to the Human Chorionic Gonadotropic Hormone (HCG) which is a glycoprotein composed of 237 amino acid (Askling et al., 1999). Gastrointestinal symptoms (vomiting, anorexia and nausea), renal tubular failure, diuretics, insulin therapy, metabolic or respiratory alkalosis hyperaldosteroidism and redistribution from plasma into cells, (Tiestz et al., 1987; Heusel et al., 2001) can cause varying degrees of decrease in plasma potassium concentration. Progesterone and estrogen were observed to increase as pregnancy advanced (Figures 1 and 2). Gastrointestinal motility is disturbed in pregnant women because of the changes of some hormone levels in the plasma, such as estrogen (E), progesterone (P), and other gastrointestinal hormones (Chang et al., 1998; Chiloiro et al., 2001). High doses of progesterone have been documented to inhibit gastric motility (Liu et al., 2002) while administration of estrogen inhibited rat gastric emptying (Chen et al., 1995). Thus, the variation in the percentages of subjects with constipation in the trimesters of pregnancy is traceable to the increasing progesterone and estrogen concentrations with advancing pregnancy (Figures 1 and 2). The anion gap for subjects in their first trimester of pregnancy was observed to be lower than that of the control subjects (Figure 1), although they were both within normal range of 10-20 mmol/L. This discrepancy in the anion gap may due to the gastrointestinal tract symptoms such as nausea, anorexia and vomiting in the first trimester of pregnancy (Table 1). Furthermore, the weakness from these symptoms can presumably decrease the metabolism of skeletal muscle (Young and Bermes, 1999), consequently increasing sodium and potassium excretion and a reduction in serum sodium and potassium concentrations (Table 2). Since these electrolytes are strong cation determinants of the anion gap a reduction in their plasma value from increased excretion will ultimately reduce the anion gap. The low anion gap also suggests that these gastrointestinal tract symptoms observed this study may have reduced the protein content of the body. Patients with pregnancy induced hypertension with varying degrees of proteinuria and hypoalbuminemia 
have been found to have a low anion gap compared to their counterparts who have an uncomplicated pregnancy (Kirschbaum and Peng, 2000). The anion gap in the second trimester of pregnancy was comparable with the pre-pregnancy state (figure 1). This may be due to the fact that symptoms such as vomiting, nausea and anorexia which are close associates of the first trimester of pregnancy have abated (Table 1). Furthermore, the second trimester of pregnancy is a relatively stable period and its stability traverses the gastrointestinal, renal, cardiovascular and other physiologic systems of the body. The cardiovascular stability of the second trimester is reflected the unchanged blood pressure in the second trimester of pregnancy.

Fluid retention accounts for between 9 and $10 \mathrm{~kg}$ of the average maternal weight gain (Richard and Emerson, 2002). Nocturia is common and increases with advancing gestation. In a survey of 256 pregnant women, 86 percent reported nocturia by the third trimester, with 20 percent of women indicating they voided three or more times nightly (Rasmussen and Nielsen, 1988). This is consonance with this study where $90 \%$ of the subjects in the third trimester of pregnancy reported nocturia (Table 1). The major cause of nocturia appears to be that pregnant women excrete larger amounts of sodium and water during the night than non-pregnant women. In the latter stages of pregnancy, this may be partially attributable to nocturnal mobilization of dependent edema in the lateral position. Several studies have described an increase in urgency and urinary incontinence during pregnancy (Van Brummen et al., 2006) to be due to uterine pressure on the bladder, hormonal effects on the suspensory ligaments of the urethra, and/or altered neuromuscular function of the urethral striated sphincter (Weidner et al., 2009).

Richard and Emerson (2002) also reported that sodium and total osmolality were reduced during the last week of pregnancy despite the salt retention, suggesting increased fetal usage. However, despite this reported reduction in osmolality from their study, we did not observe a change in anion gap (figure 1) in our study.

Conclusion: The first trimester of pregnancy predisposes women to a relatively low anion gap compared to the second and third trimester of pregnancy. This is because of the high percentage of gastrointestinal tract symptoms such as vomiting which can reduce plasma sodium and potassium. Although, the anion gap was within normal range, the relatively low anion gap can easily be complicated when these gastrointestinal tract symptoms are exacerbated. This should be taken into consideration in the management of this group of subjects during their ante natal clinics.

\section{REFERENCES}

Askling, J; Erlandsson, G; Kaijser, M; Akre, O; Ekbom, A (1999). Sickness in pregnancy and sex of a child. Lancet. 354 (9195): 2053. Doi: 10.1016/50140-6736(99) 04239-7

Chang, F Y; Lee, S D; Yeh, G H; Lu, C C; Wang, P S; Wang, S W (1998). Disturbed small intestinal motility in the late rat pregnancy. Gynecol Obstet Invest. 45:221-224

Chen, T S; Doong, M L; Chang, F Y; Lee, S D; Wang, P S (1995). Effects of sex steroid hormones on gastric emptying and gastrointestinal transit in rats. Am J Physiol.268: 171-176

Chiloiro, M; Darconza, G; Piccioli, E; De Carne, M; Clemente, C; Riezzo, G (2001). Gastic emptying and orocecal transit time in pregnancy. $J$ Gastroenterol. 36: 538-543

Coffeys Boyles, S H; Ness, R; Grisso, JA; Markovic, J; Bromberger, J; CiFelli, D (2000). Dietary reference intake for energy. Health Psychol. 19:510-514.

Gabow, PA; Kaehny, WD; Fennessey, PV; Goodman, SI; Gross, PA; Schrier, RW (1980). "Diagnostic importance of an increased serum anion gap". N. Engl. J. Med. 303 (15): 854-8.

Heusel, J W; Siggaard - Anderson, O; Scott, M G (2001). Physiology and disorders of water, Electrolytes and Acid -Base Metabolism. In: Titz Fundamentals of clinical chemistry $5^{\text {th }}$ edition. Burtis, C. A. and Ashwood, E. R. (editors), W. B. Saunders, Philadelphia Pp 723746.

Kirschbaum, B; Peng, T (2000). The anion gap associated with pregnancy-induced hypertension. Nephrol. 53(4):264-268

Kirschbaum, B; Sica, D; Anderson, F P (1999). "Urine electrolytes and the urine anion and osmolar gaps". The Journal of Laboratory and Clinical Medicine. 7-604 133: 597-604.

Kirwan, J P; Hauguel-de, M S; Lepercq, J; Challier J C; Huston-Presley, L; Friedman, Kalhan S C; Catalano, P M (2002). TNF-alpha is a predictor 
of insulin resistance in human pregnancy. Diabetes. 51:2207-2213

Liu, C Y; Chen, L B; Liu, P Y; Xie, D P; Wang, P $S$ (2002). Effects of progesterone on gastric emptying and intestinal transit in male rats. World J Gastroenterol. 8(2):338-341

Magoshes, M; Vallee, B L (1956). Flame Photometry and Spectrometry. New York J.

Intern.Sci.2(1):13 - 16.

Majzoub, M M; Walters, W A; Smith, R (2000). Prediction and early diagnosis of preterm labour - a critical review. Obstet Gynecol Survey.48:209-225.

Oh, M S; Carroll, H J (1977). "The anion gap". N. Engl. J. Med. 297 (15): 814-7.

Rasmussen P E and Nielsen F R (1988). Hydronephrosis during pregnancy: a literature survey. Eur. J. Obstet. Gynecol. Reprod. Biol. 27:249.

Richard K H G; Emerson K (2002). Physiological response to pregnancy at rest and during exercise. J Appl Physiol. 36:529-543.

Sala, C; Campise M; Ambroso G; Motta T; Zanchetti A; Morganti A (1995). A trial natriuretic peptide and hemodynamic changes during normal human pregnancy. Hypertension. 25:631-636.

Schales, O; Schales, S S (1941). A Simple and Accurate Method for Determination of Chloride in Biological Fluids. J. Biol. Chem. 140 (5); 879 $-882$.

Tietz, N W; Pruden, E L; Saggaard - Anderson, O (1987). Electrolyte. In Fundamentals of Clinical Chemistry $3^{\text {rd }}$ edition. Tietz, N.W. (editor), W.B. Saunders, Philadelphia. Pp 614 -624.

Van Brummen, H J; Bruinse, H W; Van der Bom, J $\mathrm{G}$ (2006). How do the prevalences of urogenital symptoms change during pregnancy? Neurourol. Urodyn. 25:135.

Van Slyke, D D; Neil, F M (1924). The Determination of Gases in Blood and other Solutions. J. Biol. Chem. 6(6); 523.

Weidner, A C; South, M M; Sanders, D B; Stinnett, S $S$ (2009). Change in urethral sphincter neuromuscular function during pregnancy persists after delivery. Am. J. Obstet. Gynecol. 201:529.e1.

Young, D B; Bernes, EW (1999). Specimen collection and other preanalytical variables. In Tietz Fundamental of Clinical Chemistry $5^{\text {th }}$ edition. Burtis C.A. and Ashwood, E.T. (editors), W.B. Saunders, Philadelphia. Pp 3054.

Zavalza-Gómez, A $\quad$ B, Anaya-Prado, R; RincónSánchez, A R; Mora-Martínez, J M (2008) Adipokines and insulin resistance during pregnancy. Diabetes Res Clin Pract. 80(1):8-15. 